\title{
Complementary and alternative exercise for fibromyalgia: a meta-analysis
}

\author{
This article was published in the following Dove Press journal: \\ Journal of Pain Research \\ 26 March 2013 \\ Number of times this article has been viewed
}

\section{Scott David Mist \\ Kari A Firestone \\ Kim Dupree Jones}

Fibromyalgia Research and Treatment Group, School of Nursing, Oregon Health and Science University,

Portland, OR, USA
Correspondence: Scott David Mist

4I I 6 SE Oak St, Portland,

OR 972।4, USA

Tel +I 5034944326

Fax +I 5032396312

Email mists@ohsu.edu
Abstract: Complementary and alternative medicine includes a number of exercise modalities, such as tai chi, qigong, yoga, and a variety of lesser-known movement therapies. A meta-analysis of the current literature was conducted estimating the effect size of the different modalities, study quality and bias, and adverse events. The level of research has been moderately weak to date, but most studies report a medium-to-high effect size in pain reduction. Given the lack of adverse events, there is little risk in recommending these modalities as a critical component in a multimodal treatment plan, which is often required for fibromyalgia management.

Keywords: fibromyalgia, exercise, complementary and alternative, efficacy, safety

\section{Introduction}

Fibromyalgia (FM) is a debilitating chronic pain condition affecting $\sim 15$ million persons in the USA and is one of the more severe disorders on the continuum of persistent pain. ${ }^{1-4} \mathrm{FM}$ results in profound suffering, including widespread musculoskeletal pain and stiffness, fatigue, disturbed sleep, dyscognition, affective distress, and very poor quality of life. ${ }^{5,6}$ Among FM patients, 20\%-50\% work few or no days despite being in their peak wage-earning years. ${ }^{6,7}$ Disability payments are received by $26 \%-55 \%$ of FM patients compared with the national average of $2 \%$ of patients who receive disability payments from other causes. ${ }^{7-9}$ Furthermore, health care costs are three times higher among FM patients compared with matched controls. ${ }^{9}$

Diminished aerobic fitness in FM has been documented for almost three decades, and recent studies report that the average 40-year-old with FM has fitness findings expected for a healthy 70 to 80-year-old, and FM has now also been associated with increased mortality. ${ }^{2,311-14}$ Tailoring exercise to patients with FM requires an understanding of the relevant pathophysiology. FM is likely due in part to altered pain processing in the central and peripheral nervous system. ${ }^{15-17}$ Additional pathophysiologic factors include genetic predispositions, autonomic dysfunction, and emotional, physical, or environmental stressors. ${ }^{18}$ Neurohormonal and inflammatory dysfunctions are implicated in muscle microtrauma and ischemia, a potent pain generator during and after exercise. ${ }^{15,18-24}$ The majority of persons with FM have four or more comorbid pain or central sensitivity disorders, including irritable bowel/bladder, headaches, pelvic pain, regional musculoskeletal pain syndromes (such as low back pain), chronic fatigue, and restless leg syndromes, suggesting shared pain processing in these common comorbidities. ${ }^{25-27}$ Multiple symptoms and poor physical function are underpinned by physiologic abnormalities found in FM and other chronic pain conditions. 
Drug therapies for FM offer some help, improving pain by $\sim 30 \%$ and function by $\sim 20 \%$. Drug access and costs are challenging, however, as none are available in generic formulation. Further, they carry safety concerns and may produce side effects, such as nausea, edema, weight gain, or tachycardia. ${ }^{27-31}$ Unfortunately, no new FM drugs are in Phase III testing or under Food and Drug Administration (FDA) review, shifting the urgency to the development of novel, safe, effective nonpharmacological strategies, including exercise. ${ }^{32}$

Based on results of over 100 studies, exercise has been strongly recommended as an adjunct to drug therapy for FM. ${ }^{33-36}$ Of these studies, approximately $80 \%$ are aerobic or mixed-type (aerobic, strength, flexibility). ${ }^{37-44}$ New data have emerged since these key position statements were published. Namely, a meta-analysis of studies with low attrition concluded that immediately postintervention, high quality aerobic or mixed modality exercise reliably restored physical function or fitness $(d=0.65)$ and health-related quality of life $(\mathrm{d}=-0.40)$, while exerting no significant effects on sleep $(d=0.01)$. Effect sizes for pain were small $(d=-0.31)$ and not sustained at follow up $(\mathrm{d}=0.13) .{ }^{41}$ Similarly, 14 strength or stretching studies consistently demonstrated improvements in fatigue and physical function but inconsistently improved other FM symptoms. ${ }^{39,42}$ Studies included in the meta-analysis had a median attrition of $67 \%$ (range $27 \%-90 \%$ ), suggesting that the interventions themselves were not acceptable. Some early programs dosed the intervention too high (exercise frequency, intensity, and timing) or required medication washout, leading to an attrition rate averaging approximately $40 \%$. Others selected inappropriate exercise modalities, such as running, fast dancing, or high-intensity aerobics, resulting in $62 \%-67 \%$ attrition. ${ }^{45,46}$

In search of more comprehensive and continued symptom relief, FM patients have been increasingly adopting complementary and alternative exercise therapies, such as qigong, tai chi, yoga, and a variety of lesser-known movement therapies. ${ }^{47,48}$ Qigong and tai chi both have origins in the Chinese martial arts. They involve physical movement integrated with mental focus and deep breathing. They seek to cultivate and balance qi (chi), which is sometimes translated as "intrinsic life energy." Yoga is "a union of mind and body" with origins in ancient Indian philosophy. In yoga, physical postures ("asanas") are generally practiced in tandem with breathing techniques ("pranayama") and meditation or relaxation.

Langhorst et $a l^{49}$ recently published a meta-analysis of randomized controlled trials (RCTs) on meditative movement in FM, concluding that these modalities were safe and effective for selected FM symptoms. The aim of this paper is to extend Langhorst's work by providing a comprehensive review of a broader array of land-based complementary and alternative medicine (CAM) FM exercise studies, including early-stage research. For the purposes of this review, exercise is defined as planned, structured physical activity whose goal is to improve one or more of the major components of fitness - aerobic capacity, strength, flexibility, or balance. CAM is defined as "a group of diverse medical and health care systems, practices, and products that are not generally considered to be part of conventional medicine." ${ }^{\prime 50}$

\section{Material and methods Literature search strategy}

Electronic databases were screened during October 2012, including SciVerse Scopus, Cumulative Index to Nursing and Allied Health Literature (CINAHL), PubMed/Medline, Cochrane Library, and PsychInfo. The key medical subject heading $(\mathrm{MeSH})$ terms for initial inclusion were "fibromyalgia" and "fibromyalgia syndrome" combined with "yoga," "tai chi," "pilates," "taiji," and "qigong." To maximize the search results, no search limitations of language, year, or study design were implemented. Additional studies were identified through the bibliographies of selected studies and personal contact with researchers in the field.

\section{Selection criteria}

To determine their initial eligibility, all potential studies were retrieved in full text and reviewed for the inclusion criteria. All three authors independently screened all identified full-text articles, to determine whether the study met the inclusion criteria. To be included in this review, studies had to meet the following criteria: (1) enrollment of participants 21 years of age and older who met the standardized criteria for FM diagnosis, (2) study intervention met the definitions for CAM and land-based exercise, and (3) inclusion and reporting of pre- and post-Fibromyalgia Impact Questionnaire (FIQ) total score or numeric pain rating scale scores. ${ }^{51,52}$ This means that CAM studies with very low levels of exertion, such as studies of body awareness therapies, breathing studies, and mindfulness-based stress reduction (which generally offers very brief yoga in two out of eight sessions), were not included. Additionally, we excluded water-based CAM therapies, such as tai chi in water and yoga/breathing in water, as it is unclear whether the benefit derived from balneotherapeutic effects or physical movement and mindful techniques (Figure 1). ${ }^{53,54}$ 


\section{Data extraction}

All review authors participated in data extraction. Data were extracted in the following content areas: study design, type of CAM exercise, sample size, subject characteristics (age and gender), treatment duration, frequency and dose, adherence to treatment, attrition rates, and outcome variables and results. Any discrepancies between authors were discussed and consensus obtained. When studies did not include enough information to calculate the effect size estimates on pain, the authors were contacted to request the data required for a complete statistical analysis. Most of these reported point estimates rather than effect sizes. All studies for which effect sizes could not be calculated, were excluded from this review.

\section{Statistical analysis}

The analysis was completed using Comprehensive Meta Analysis software, Version 2.2.064 (Biostat Inc., Englewood, NJ, USA). Standard formulas were used to calculate standardized mean differences and standard errors. ${ }^{55}$ Overall estimates of treatment effect used a random effects metaanalysis. ${ }^{56}$ Subgroup analyses were conducted with respect to treatment modality. A common among-study variance component across subgroups was not used when calculating the effect size of the individual modalities.

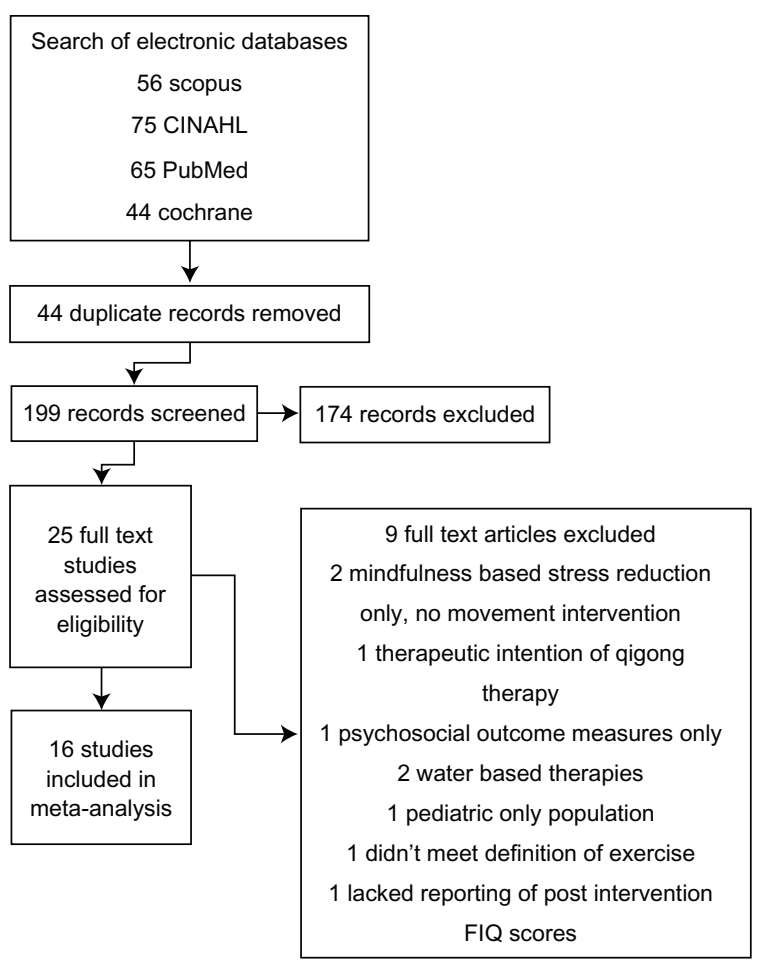

Figure I Search strategy results.

Abbreviations: CINAHL, Cumulative Index to Nursing and Allied Health Literature; FIQ, Fibromyalgia Impact Questionnaire.

\section{Quality assessment}

The methodological quality of the selected studies was assessed using the Jadad score, ${ }^{57}$ assessing for randomization, blinding, and clear explanations for study dropouts. While Jadad scoring is intended for RCTs, the authors thought that it was a good, if simple, measure of methodological quality, allowing nonrandomized trials in this review the possibility of a score of 0 or 1 and RCTs a maximum score of 3 . Normally the Jadad score has a range of 0 to 5, but as it is not possible to blind the interventionist to the treatment in CAM exercise, the maximum achievable score is 3 . The average score for the studies in this review was 1.7 (range 1 to 3 ).

\section{Sensitivity and validity analysis}

A funnel plot was constructed of standard differences (Std diff) in means by standard errors, with two standard deviations displayed. A random distribution of studies indicated a low publication bias. A regression of the Jadad score on the Std diff in means was calculated. The slope is indicative of publication bias by quality of study. A slope of zero indicates that there was no bias.

\section{Results Study design}

As the field has a relatively low number of reported RCTs, we included time-series trials. Due to this limitation, the relative study strength was moderately low. Time-series trials were adjusted for the relative overestimation of strength. However, one can see that the time series still represented some of the largest reported effects. Table 1 reports the details of each study.

\section{Participants}

A total of $832 \mathrm{FM}$ patients participated in the reviewed studies, with 490 allocated to the CAM exercise interventions. The median of the sample size for the CAM exercise interventions was 23 (range 6-64). The median percentage of patients completing the study was $81 \%$, and there was no significant difference in dropout among those studies that included a comparison arm. ${ }^{58-75}$ In all of the studies, the FM diagnosis was made in accordance with the American College of Rheumatology 1990 criteria. $^{52}$

\section{Outcomes}

In all studies, except for one by Curtis et al, the FIQ total score or FIQ Pain Score was used as the primary outcome. The Curtis et al study used the McGill Pain Questionnaire, and in this case, the total McGill Pain Questionnaire was 


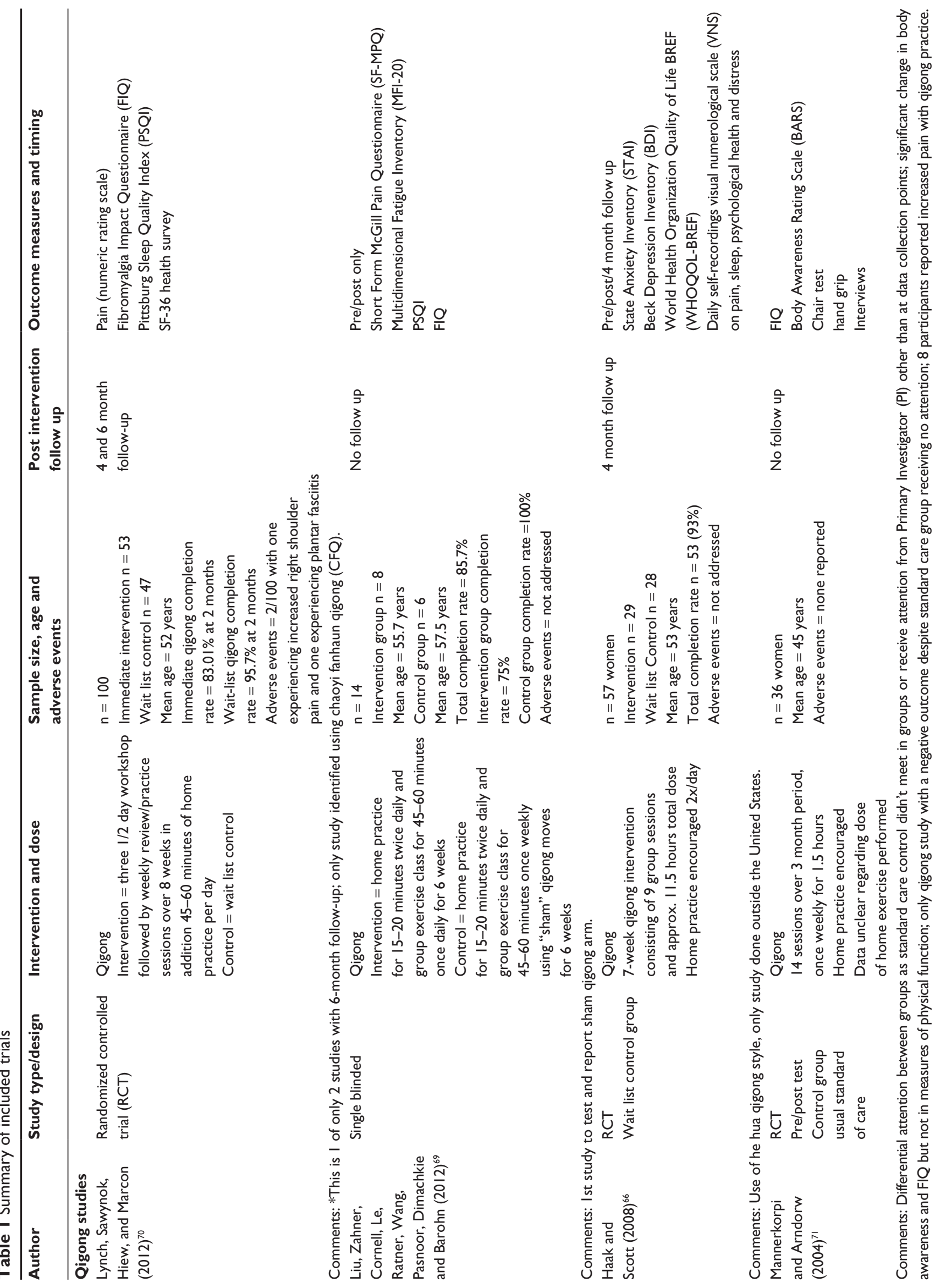



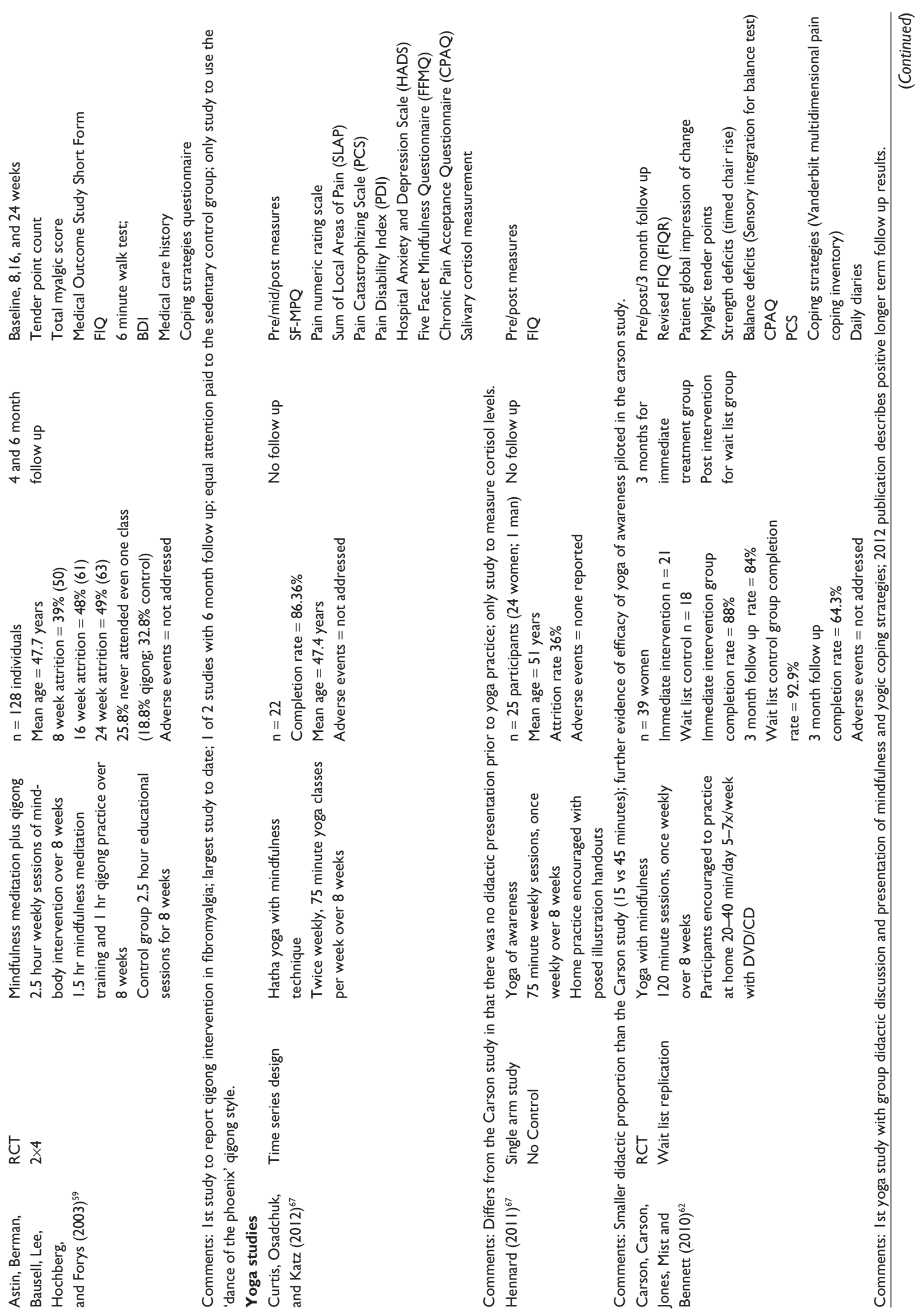

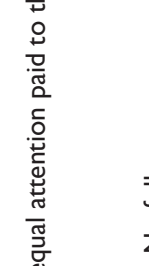

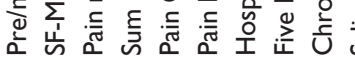

壱
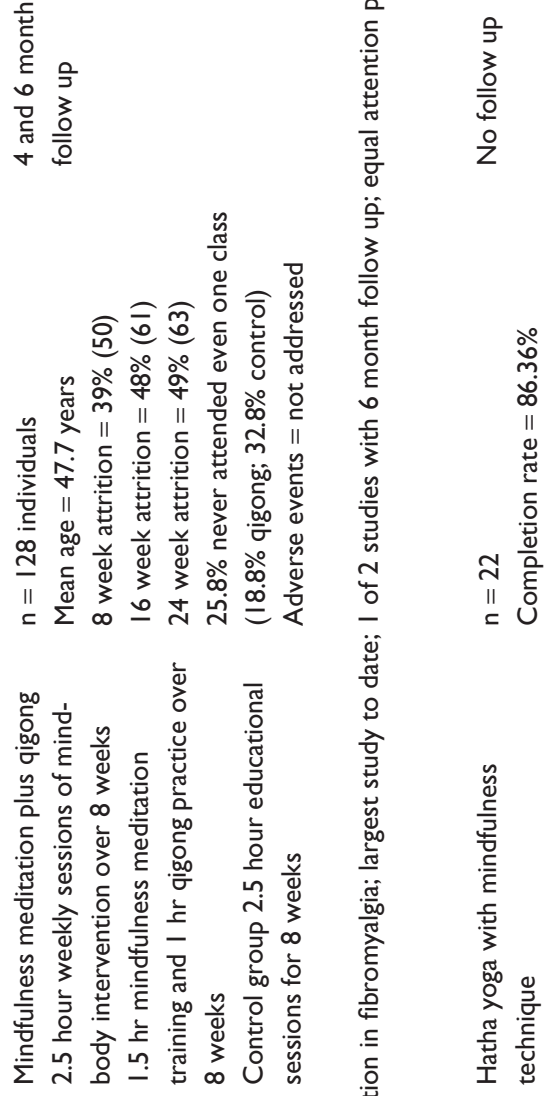

$\checkmark$ प

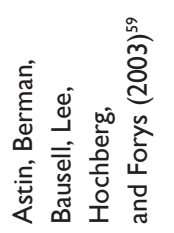

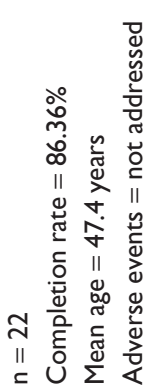
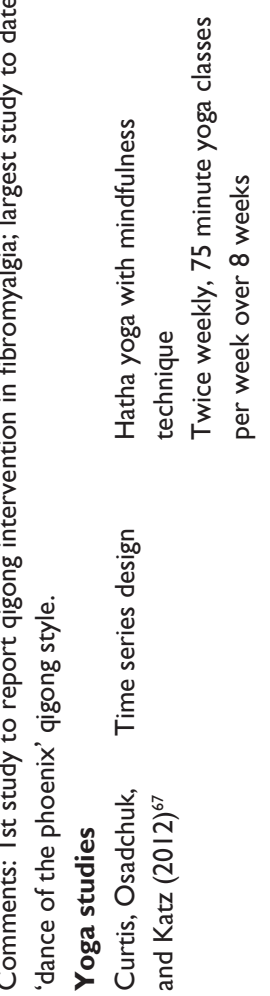


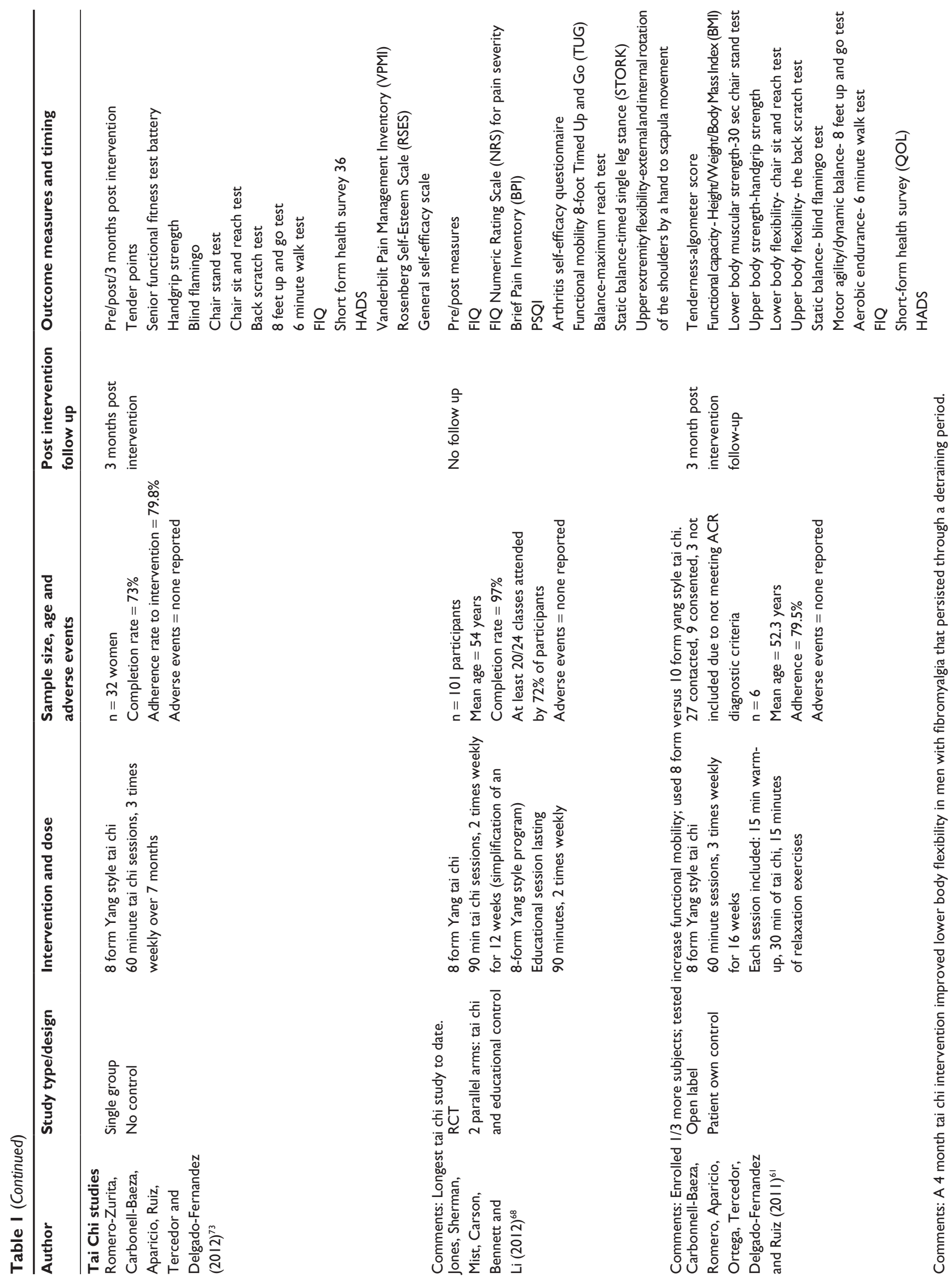




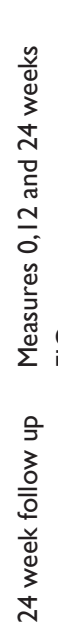

希

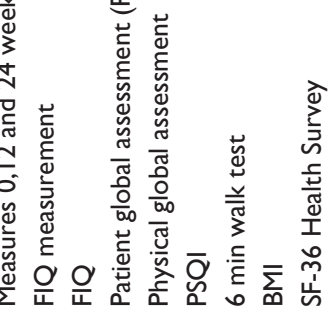

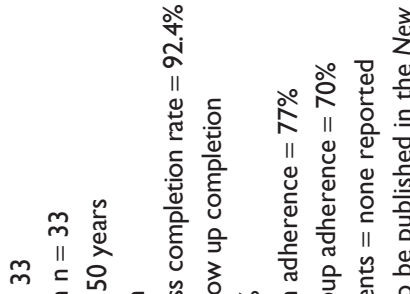

II ᄃ

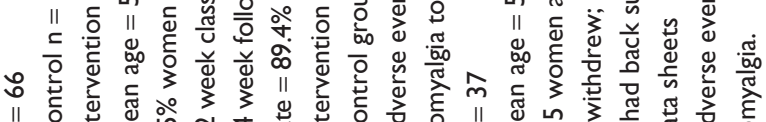

II

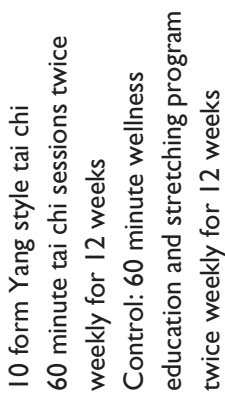

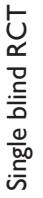

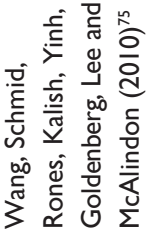

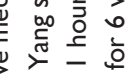
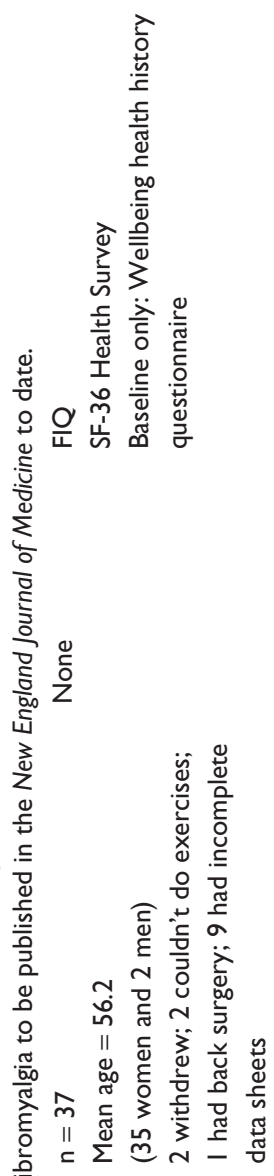

हे

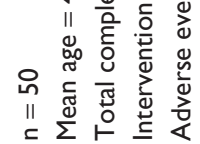

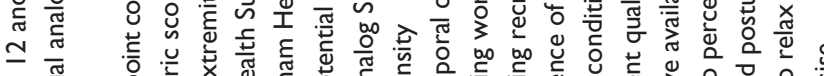

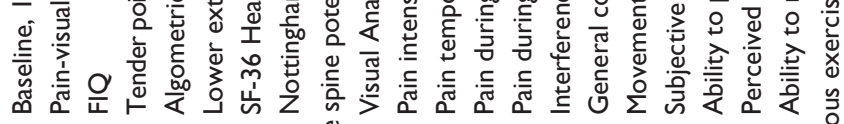

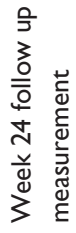

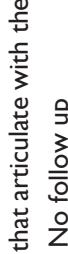

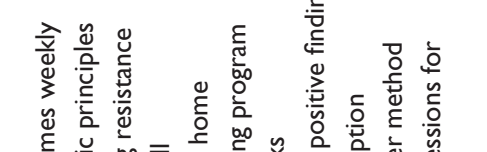

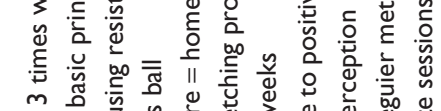

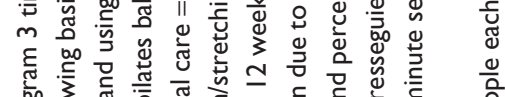

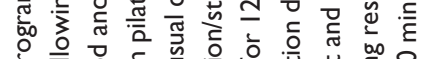

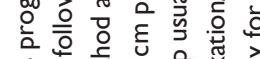

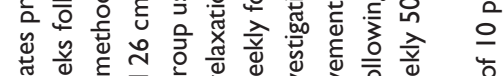
言过

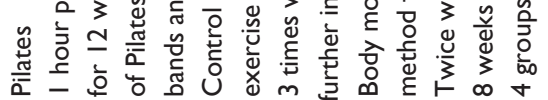

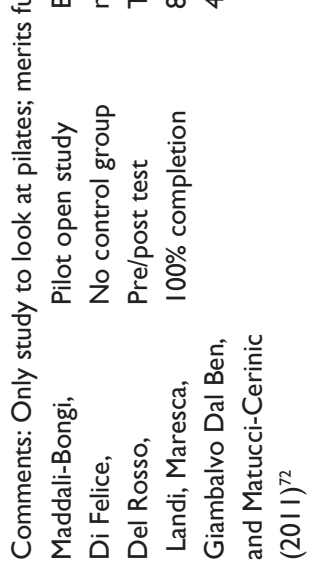




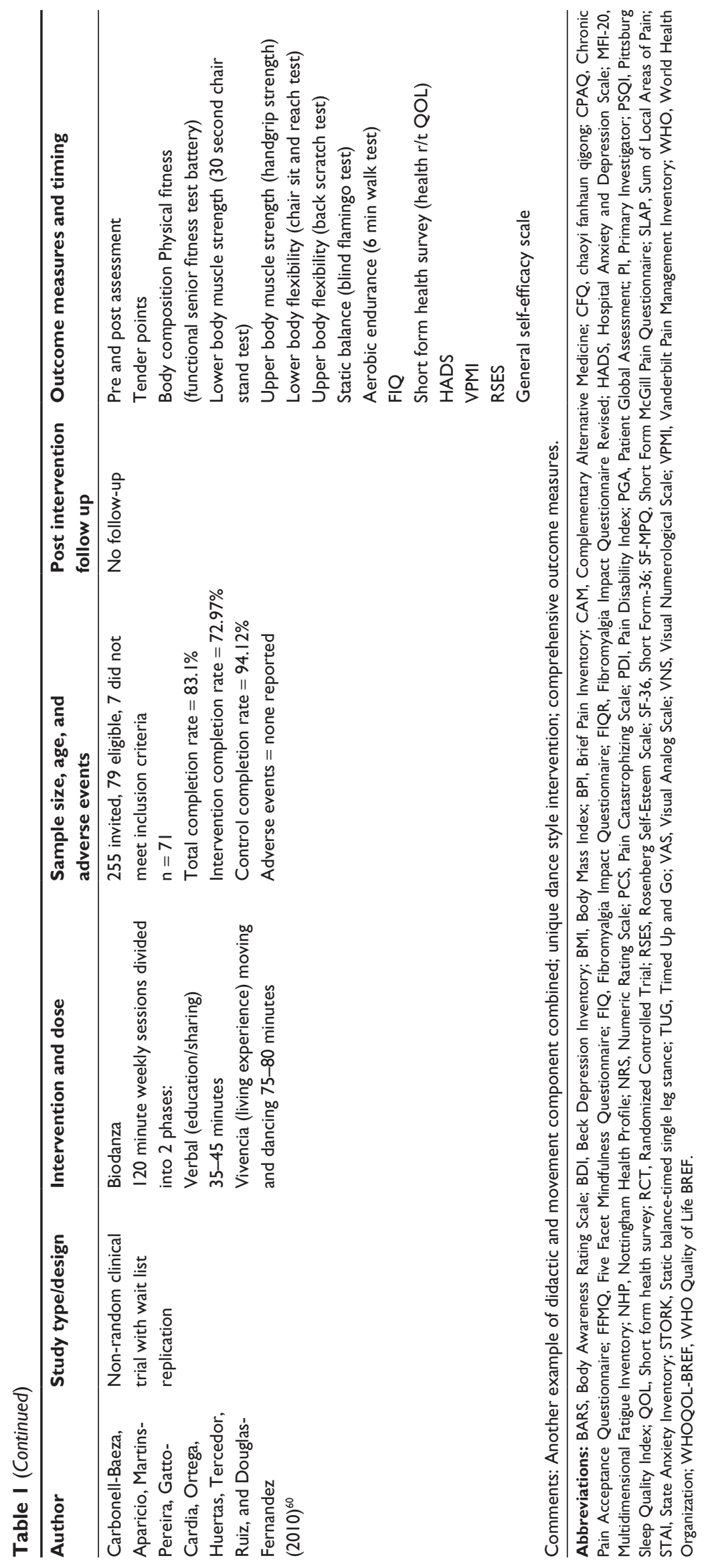


Study name Comparison

\begin{tabular}{|c|c|c|c|c|c|c|c|c|}
\hline & & $\begin{array}{c}\text { Std diff } \\
\text { in means }\end{array}$ & $\begin{array}{l}\text { Standard } \\
\text { error }\end{array}$ & Variance & $\begin{array}{c}\text { Lower } \\
\text { limit }\end{array}$ & $\begin{array}{l}\text { Upper } \\
\text { limit }\end{array}$ & Z-value & $P$-value \\
\hline Astin ${ }^{59}$ & Qigong & 0.053 & 0.177 & 0.031 & -0.294 & 0.399 & 0.299 & 0.765 \\
\hline Haak $^{66}$ & Qigong & 0.618 & 0.271 & 0.074 & 0.086 & 1.149 & 2.279 & 0.023 \\
\hline Liu $^{69}$ & Qigong & 0.207 & 0.541 & 0.293 & -0.854 & 1.269 & 0.383 & 0.702 \\
\hline Mannerkopi ${ }^{7^{71}}$ & Qigong & -0.418 & 0.433 & 0.187 & -1.265 & 0.431 & -0.965 & 0.334 \\
\hline Stephens ${ }^{76}$ & Qigong & 1.124 & 0.439 & 0.193 & 0.263 & 1.985 & 2.558 & 0.011 \\
\hline \multirow[t]{2}{*}{ Lynch $^{70}$} & Qigong & 1.197 & 0.230 & 0.053 & 0.746 & 1.648 & 5.200 & 0.000 \\
\hline & & 0.472 & 0.113 & 0.013 & 0.250 & 0.693 & 4.177 & 0.000 \\
\hline
\end{tabular}

Figure 2 Qigong forest plot.

Abbreviations: std diff, standard difference; $\mathrm{Cl}$, confidence interval.
Std diff in means and $95 \% \mathrm{CI}$

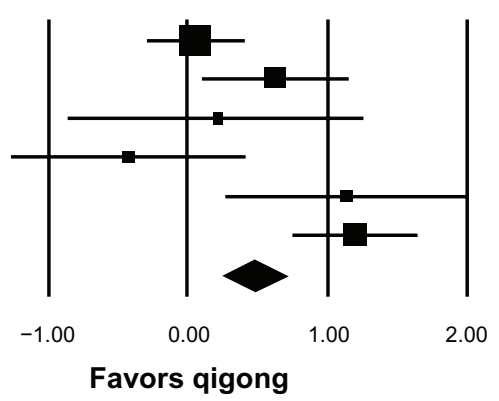

Std diff in means and $95 \% \mathrm{Cl}$

\section{Statistics for each study}

\begin{tabular}{lccccccc} 
& $\begin{array}{c}\text { Std diff } \\
\text { in means }\end{array}$ & $\begin{array}{c}\text { Standard } \\
\text { error }\end{array}$ & \multicolumn{7}{c}{ Variance } & limit & limit & Z-value & $P$-value \\
Tai chi & 0.187 & 0.412 & 0.170 & -0.620 & 0.995 & 0.455 & 0.649 \\
Tai chi & 0.897 & 0.212 & 0.045 & 0.481 & 1.312 & 4.227 & 0.000 \\
Tai chi & 0.921 & 0.249 & 0.062 & 0.433 & 1.408 & 3.700 & 0.000 \\
Tai chi & 4.557 & 0.540 & 0.292 & 3.498 & 5.616 & 8.435 & 0.000 \\
Tai chi & 1.358 & 0.284 & 0.081 & 0.800 & 1.915 & 4.775 & 0.000 \\
& 1.137 & 0.129 & 0.017 & 0.884 & 1.390 & 8.814 & 0.000
\end{tabular}

Figure 3 Tai chi forest plot.

Abbreviations: std diff, standard difference; $\mathrm{Cl}$, confidence interval.
Study name Comparison

$\begin{array}{ll}\text { Carbonell-Baeza }^{61} & \text { Tai chi } \\ \text { Jones }^{68} & \text { Tai chi } \\ \text { Romero-Zurita }^{73} & \text { Tai chi } \\ \text { Taggart }^{74} & \text { Tai chi } \\ \text { Wang }^{75} & \text { Tai chi }\end{array}$
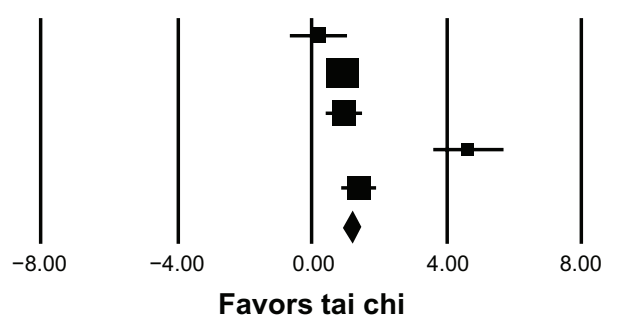

Favors tai chi

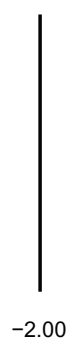

$-2.00$
Study name Comparison

\begin{tabular}{|c|c|c|c|c|c|c|c|c|}
\hline & & $\begin{array}{c}\text { Std diff } \\
\text { in means }\end{array}$ & $\begin{array}{c}\text { Standard } \\
\text { error }\end{array}$ & Variance & $\begin{array}{l}\text { Lower } \\
\text { limit }\end{array}$ & $\begin{array}{l}\text { Upper } \\
\text { limit }\end{array}$ & $Z$-value & $P$-value \\
\hline Carson ${ }^{62}$ & Yoga & 0.718 & 0.294 & 0.086 & 0.143 & 1.294 & 2.445 & 0.014 \\
\hline Curtis ${ }^{64}$ & Yoga & 0.191 & 0.231 & 0.054 & -0.263 & 0.645 & 0.825 & 0.409 \\
\hline \multirow[t]{2}{*}{ Hennard $^{67}$} & Yoga & 0.614 & 0.329 & 0.108 & -0.031 & 1.258 & 1.867 & 0.062 \\
\hline & & 0.445 & 0.159 & 0.025 & 0.133 & 0.757 & 2.795 & 0.005 \\
\hline
\end{tabular}

Figure 4 Yoga forest plot.

Abbreviations: std diff, standard difference; $\mathrm{Cl}$, confidence interval.
Std diff in means and $95 \% \mathrm{Cl}$

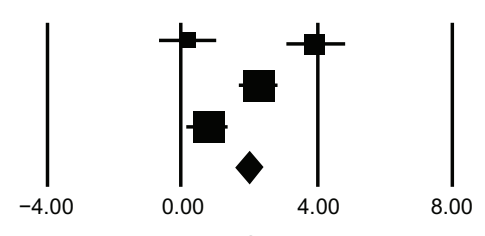

Favors other CAM

Figure 5 Other CAM forest plot.

Abbreviations: BMP, body movement and perception therapy; CAM, complementary and alternative medicine; std diff, standard difference; $\mathrm{Cl}$, confidence interval. 


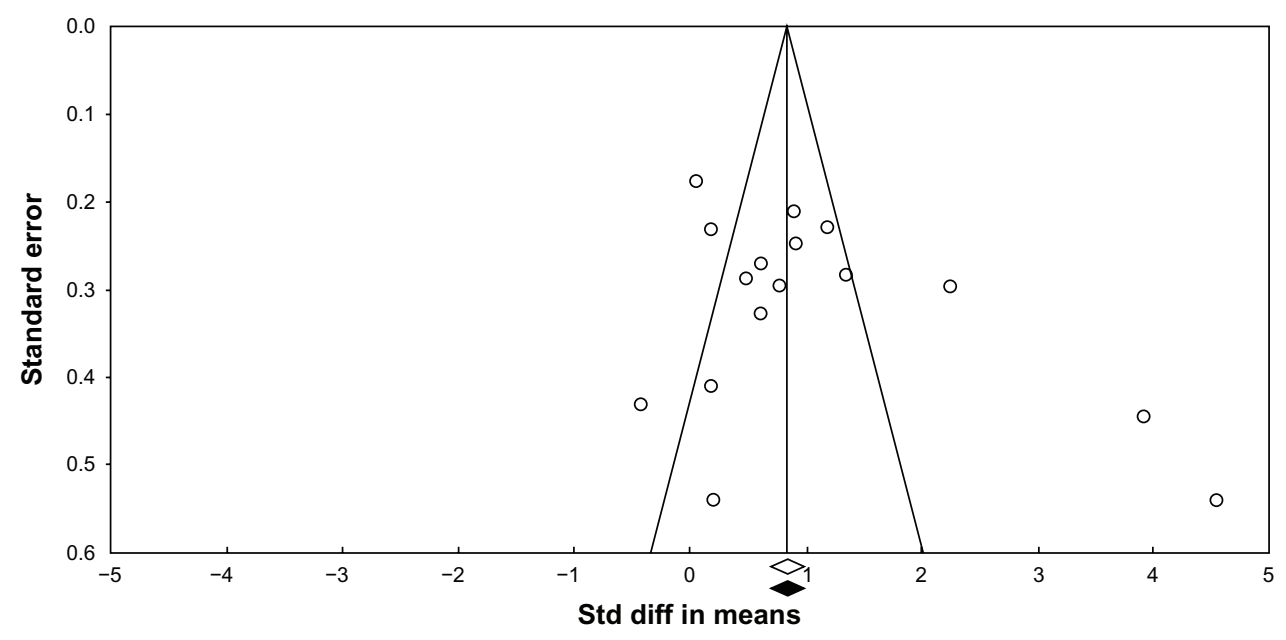

Figure 6 Funnel plot of standard error by standard difference in means. Abbreviation: std diff, standard difference.

analyzed. ${ }^{64}$ Most studies reported both pre- and posttreatment scores, with a number reporting longer-term follow ups. For the purpose of the current analysis, only pre- and post-effects were assessed. There were no significant differences among the baseline means and standard deviations across the studies.

\section{Meta-analyses}

The standard difference in means $(0.84)$, and standard errors (0.07) for CAM exercise, indicates a statistically significant $(P=0.00)$ and positive outcome. The individual forest plots for qigong, tai chi, yoga, and all others are reported in Figures 2-5 respectively. With the exception of two studies, all studies reported positive outcomes. ${ }^{71}$ Of those not reporting positive outcomes, Mannerkorpi and Arndorw ${ }^{71}$ found no difference between 14 weeks of qigong versus a sedentary "usual care" control in 36 FM patients. Likewise,
Carbonell-Baeza et al ${ }^{61}$ concluded that a 4-month male tai chi study $(n=6)$ was negative for symptom improvement.

\section{Sensitivity analyses}

A funnel plot of the Std diff in means indicates that if the standard difference in means $(0.84)$ is true, there is little evidence for reporting bias. The majority of studies fell within two standard deviations, with an equal number of studies falling outside this on either side of the plot (Figure 6). A regression of the Jadad scores on the standard difference of means indicates more variation reported in the lower scores and less in the higher scores, with a slight increase in the slope seen with higher scores (Figure 7).

\section{Validity analysis}

There was a significant amount of heterogeneity in the studies presented in this analysis. This can be seen in the means and

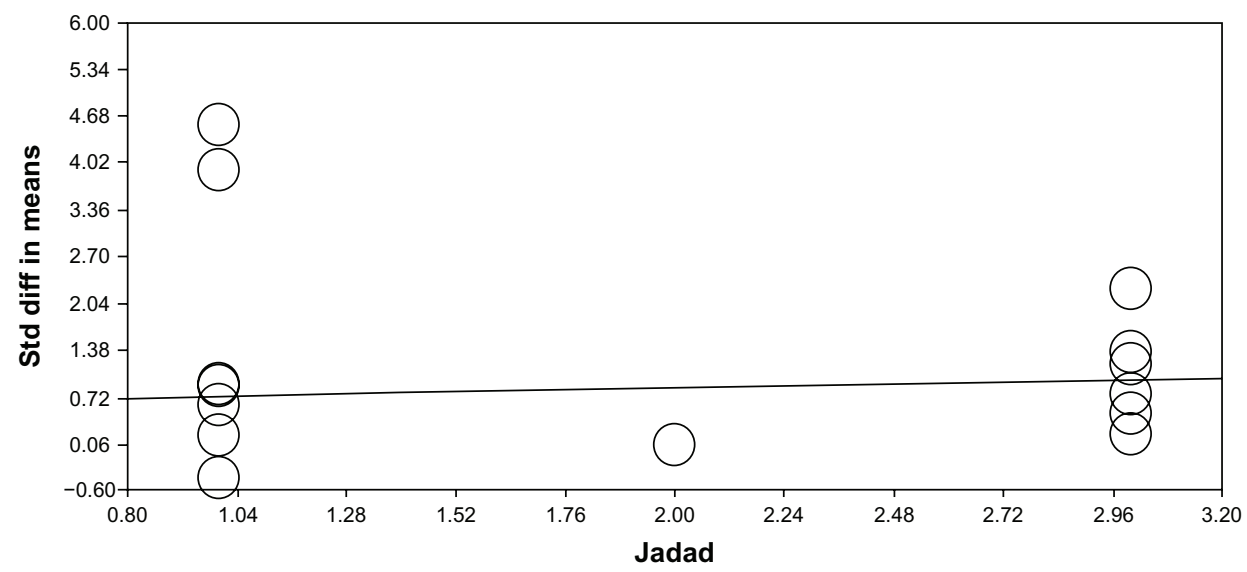

Figure 7 Regression of Jadad score on standard difference in means (Jadad et al, 1996). ${ }^{57}$ Abbreviation: std diff, standard difference. 
confidence intervals in the subplots. The distributions of the forest plots suggest that the results are randomly distributed, indicating that the results are mostly consistent within each type of exercise.

\section{Discussion}

The data presented support the likely safety of CAM exercise interventions, as 832 participants were enrolled in 16 studies and $81 \%$ completed the studies without differential attrition by study arm or exercise modality. ${ }^{58-75}$ Only one study reported negative side effects (increased shoulder pain and plantar fasciitis) in two study participants. ${ }^{70}$ All studies reported that there were no serious adverse events.

The data also support some degree of efficacy of several of the CAM exercise interventions in improving overall FM symptoms and physical function. Taken as a whole, the data do not indicate that any one intervention type is consistently superior to another, though the strongest effects were for the exercise modalities with the largest number of trials: qigong (Std diff in means 0.47; $P<0.000$ ) and tai chi (Std diff in means 1.14; $P<0.000$ ). Further support for qigong comes from a trial excluded from this analysis. Stephens et $\mathrm{al}^{76}$ randomized 30 children (ages 8-18) with FM to aerobics or qigong. There was no difference between study arms, although qigong was intended to be the control group. The qigong group did demonstrate significant within-group changes, indicating that pediatric CAM exercise interventions may be a promising area of research. This is critical, as few interventions address pediatric FM even though its recognition as a valid diagnosis is increasing. This may indicate that mind-body exercises may be a feasible therapeutic option across a wider range of developmental states. ${ }^{76-80}$

Complete data were only available for three yoga trials (two were open labeled) but were positive (Std diff in means 0.45; $P<0.015) .{ }^{62,64,67}$ Additional support for the benefit of yoga is found in two studies that are not represented in the analyses due to missing data. da Silva et $\mathrm{al}^{65}$ randomized 40 women with FM into an individually delivered intervention of "relaxing" yoga with or without additional tui na (massage). Both groups experienced clinically and statistically significant reductions in FIQ total scores, but there was no difference between treatment arms. Another trial $(\mathrm{n}=10)$ noted a $28 \%$ improvement in FIQ total scores following eight weeks of gentle Hatha yoga ${ }^{81}$ Three other CAM-based exercise studies were positive, but the interventions have yet to be replicated (pilates, Biodanza, and Resseguier with body movement and perception). ${ }^{58,60,72}$ Pilates is a series of nonimpact strength, flexibility, and breathing exercises designed by Joseph Pilates to promote inner awareness and core stability. Biodanza, literally "life-dance," is a program of exercise that seeks to optimize self-development and deepen self-awareness. It most often uses dance, music, singing, and other movements to promote positive feelings, emotional expression, and connection to others and to nature. Resseguier is based on selected soft, low-impact gymnastic movements integrated with postural self-control, body alignment, and relaxation.

The data are consistent with an earlier rigorous report on "mindful" meditative movement therapies that concluded that these therapies were safe and effective for reducing sleep disturbances, fatigue, and depression, and improving quality of life. In subanalyses, the authors found that only yoga also relieved pain. ${ }^{50}$ However, that meta-analysis was comprised of only RCTs $(n=7)$. The current data extend these findings by demonstrating efficacy in a combination of FM symptoms and physical function, in a larger number of studies $(\mathrm{n}=16)$.

This meta-analysis shows that research in the area was at an early state (six open-labeled studies), although regressing by Jadad score showed that there was a nonsignificant difference by effect size. This may indicate that early-stage studies are not likely to overreport effect.

This study does have limitations, the greatest being that six of the studies were open labeled. Others may argue, however, that open-labeled trials are appropriate in early-phase research when safety, feasibility, and effect sizes are being determined. ${ }^{82}$ Further, because open-labeled studies were included, community-based exercise studios and instructors were tested, leading the field toward effectiveness rather than efficacy outcomes. The studies were generally small (average $\mathrm{n}=51.5$; range 6 to 128 participants), limiting their power and the ability to test multiple comparisons or to profile responders' reliability.

Another limitation is that the studies were largely conducted in middle-aged women, in America and Europe. This is important, as many CAM exercise studies have been conducted in India and China, where many of these traditions are rooted (however, those studies were not available in English or from major database sources). Moreover, differential effects may be found in men, minorities, children and elders. Another limitation is that all the trials employed a single interventionist and did not rate treatment expectancy. It is possible, therefore, that a charismatic or caring instructor, rather than the intervention itself, may have been responsible for the beneficial outcome, although this is less likely in the 
trials that have been replicated (qigong, tai chi, and yoga). Future effectiveness studies could use multiple instructors.

A goal of future studies should include the standardization of exercise protocols, including scripting for mindfulness, posture sequences, and a range of modifications based on the patient's physical ability. To date, studies have varied considerably in exercise dose and have not always provided adequate description of the intervention to allow replication. Publishing protocols in peer-reviewed journals would provide opportunities for a more detailed description of the actual intervention and for pictures of the less common poses or physical strategies. This is important because people with FM are likely to be in poor physical condition, have joint hypermobility, and poor balance, and may be at an increased risk for injury. ${ }^{42}$

Future studies should incorporate validated scales such as the revised FIQ (FIQ-R), Brief Pain Inventory, Multidimensional Fatigue Inventory, Medical Outcomes Study Sleep Scale, and Multiple Ability Self-Report Questionnaire. ${ }^{83,84}$ Full reporting of data and statistical tests will allow for more seamless comparison in future trials. Some FM exercise studies now report the number needed to treat, based on Patients' Global Impression of change (PGIC) scale, which allows for direct comparison with pharmaceutical trials. ${ }^{85}$ Similarly, work is underway to develop a responder index. ${ }^{86}$

In conclusion, the CAM-based exercise therapies reviewed are likely safe, and no serious adverse events were reported in any study. These exercise programs were somewhat efficacious for FM pain, with many studies reporting improvement in overall FM symptoms and physical function. However, the majority of studies had lower methodological quality. There is a need for large, rigorous trials with active parallel arms-such as traditional aerobic exercise compared with CAM-based exercise - to extend this body of evidence.

\section{Disclosure}

The authors report no conflicts of interest in this work.

\section{References}

1. Jain AK, Carruthers BM, van de Sande MI, et al. Fibromyalgia syndrome: Canadian clinical working case definition, diagnostic and treatment protocols - A consensus document. J Musculoskelet Pain. 2004;11(4):3-107.

2. Macfarlane GJ, McBeth J, Silman AJ. Widespread body pain and mortality: prospective population based study. BMJ. 2001;323(7314): 662-665.

3. Macfarlane GJ. Chronic widespread pain and fibromyalgia: Should reports of increased mortality influence management? Current Rheumatol Rep. 2005;7(5):339-341.
4. White KP, Harth M. Classification, epidemiology, and natural history of fibromyalgia. Curr Pain Headache Rep. 2001;5(4): 320-329.

5. Burckhardt CS, Bjelle A. Perceived control: A comparison of women with fibromyalgia, rheumatoid arthritis, and systematic lupus erythematosus using a Swedish version of the rheumatology attitudes index. Scand J Rheumatol. 1996;25(5):300-306.

6. Ledingham J, Doherty S, Doherty M. Primary fibromyalgia syndrome - an outcome study. Br J Rheumatol. 1993;32(2):139-142.

7. Wolfe F, Anderson J, Harkness D, et al. Work and disability status of persons with fibromyalgia. J Rheumatol. 1997;24(6):1171-1178.

8. Martinez JE, Ferraz MB, Sato EL, Atra E. Fibromyalgia versus rheumatoid arthritis: a longitudinal comparison of the quality of life. J Rheumatol. 1995;22(2):270-274.

9. Berger A, Dukes E, Martin S, Edelsberg J, Oster G. Characteristics and healthcare costs of patients with fibromyalgia syndrome. Int J Clin Pract. 2007;61(9):1498-1508.

10. Jones J, Rutledge DN, Jones KD, Matallana L, Rooks DS. Self-assessed physical function levels of women with fibromyalgia: a national survey. Womens Health Issues. 2008;18(5):406-412.

11. Jones KD, King LA, Mist SD, Bennett RM, Horak FB. Postural control deficits in people with fibromyalgia: a pilot study. Arthritis Res Ther. 2011;13(4):R127.

12. Carbonell-Baeza A, Aparicio VA, Sjöström M, Ruiz JR, DelgadoFernández M. Pain and functional capacity in female fibromyalgia patients. Pain Med. 2011;12(11):1667-1675.

13. Panton LB, Kingsley JD, Toole T, et al. A comparison of physical functional performance and strength in women with fibromyalgia, age- and weight- matched controls, and older women who are healthy. Phys Ther. 2006;86(11):1479-1488.

14. Jensen KB, Kosek E, Petzke F, et al. Evidence of dysfunctional pain inhibition in Fibromyalgia reflected in rACC during provoked pain. Pain. 2009;144(1-2):95-100.

15. Staud R, Nagel S, Robinson ME, Price DD. Enhanced central pain processing of fibromyalgia patients is maintained by muscle afferent input: a randomized, double-blind, placebo-controlled study. Pain. 2009; 145(1-2):96-104.

16. Robinson ME, Craggs JG, Price DD, Perlstein WM, Staud R. Gray matter volumes of pain-related brain areas are decreased in fibromyalgia syndrome. J Pain. 2011;12(4):436-443.

17. Landis CA. Sleep, pain, fibromyalgia, and chronic fatigue syndrome. Handb Clin Neurol. 2011;98:613-637.

18. Jones KD, Deodhar P, Lorentzen A, Bennett RM, Deodhar AA. Growth hormone perturbations in fibromyalgia: a review. Semin Arthritis Rheum. 2007;36(6):357-379.

19. Ross RL, Jones KD, Bennett RM, Ward RL, Druker BJ, Wood LJ. Preliminary evidence of increased pain and elevated cytokines in fibromyalgia patients with defective growth hormone response to exercise. Open Immunol. 2010;3:9-18.

20. Williams DA, Clauw DJ. Understanding fibromyalgia: lessons from the broader pain research community. J Pain. 2009;10(8):777-791.

21. Staud R. Peripheral pain mechanisms in chronic widespread pain. Best Pract Res Clin Rheumatol. 2011;25(2):155-164.

22. Elven A, Siösteen AK, Nilsson A, Kosek E. Decreased muscles blood flow in fibromyalgia patients during standardised muscle exercise: a contrast media enhanced colour Doppler study. Eur J Pain. 2006;10(2): $137-144$.

23. Ge HY, Arendt-Nielsen L, Madeleine P. Accelerated muscle fatigability of latent myofascial trigger points in humans. Pain Med. 2012;13(7): 957-964.

24. Srikuea R, Symons TB, Long DE, et al. Fibromyalgia is associated with altered skeletal muscle characteristics which may contribute to post-exertional fatigue in post-menopausal women. Arthritis Rheum. Epub November 1, 2012.

25. Yunus MB. Fibromyalgia and overlapping disorders: the unifying concept of central sensitivity syndromes. Semin Arthritis Rheum. 2007;36(6):339-356. 
26. Aaron LA, Burke MM, Buchwald D. Overlapping conditions among patients with chronic fatigue syndrome, fibromyalgia, and temporomandibular disorder. Arch Intern Med. 2000;160(2):221-227.

27. Crofford LJ, Rowbotham MC, Mease PJ, et al. Pregabalin for the treatment of fibromyalgia syndrome: results of a randomized, double-blind, placebo-controlled trial. Arthritis Rheum. 2005;52(4): 1264-1273.

28. Häuser W, Petzke F, Sommer C. Comparative efficacy and harms of duloxetine, milnacipran, and pregabalin in fibromyalgia syndrome. J Pain. 2010;11(6):505-521.

29. Mease PJ, Choy EH. Pharmacotherapy of fibromyalgia. Rheum Dis Clin North Am. 2009;35(2):359-372.

30. Mease PJ, Clauw DJ, Gendreau RM, et al. The efficacy and safety of milnacipran for treatment of fibromyalgia. a randomized, double-blind, placebo-controlled trial. J Rheumatol. 2009;36(2):398-409.

31. Russell IJ, Mease PJ, Smith TR, et al. Efficacy and safety of duloxetine for treatment of fibromyalgia in patients with or without major depressive disorder: Results from a 6-month, randomized, double-blind, placebo-controlled, fixed-dose trial. Pain. 2008;136(3): 432-444.

32. Staud R. Sodium oxybate for the treatment of fibromyalgia. Expert Opin Pharmacother. 2011;12(11):1789-1798.

33. Carville SF, Arendt-Nielsen S, Bliddal H, et al; EULAR. EULAR evidence-based recommendations for the management of fibromyalgia syndrome. Ann Rheum Dis. 2008;67(4):536-541.

34. Goldenberg DL, Burckhardt C, Crofford L. Management of fibromyalgia syndrome. JAMA. 2004;292(19):2388-2395.

35. Häuser W, Arnold B, Eich W, et al. Management of fibromyalgia syndrome - an interdisciplinary evidence-based guideline. Ger Med Sci. 2008;6:Doc14.

36. Sim J, Adams N. Systematic review of randomized controlled trials of nonpharmacological interventions for fibromyalgia. Clin J Pain. 2002;18(5):324-336.

37. Brosseau L, Wells GA, Tugwell P, et al. Ottawa panel evidencebased clinical practice guidelines for aerobic fitness exercises in the management of fibromyalgia: part 1. Phys Ther. 2008;88(7): 857-871.

38. Brosseau L, Wells GA, Tugwell P, et al. Ottawa panel evidencebased clinical practice guidelines for strengthening exercises in the management of fibromyalgia: part 2. Phys Ther. 2008;88(7): $873-886$.

39. Busch A, Schachter CL, Peloso PM, Bombardier C. Exercise for treating fibromyalgia syndrome. Cochrane Database Syst Rev. 2002(3): CD003786.

40. Häuser W, Klose P, Langhorst J, et al. Efficacy of different types of aerobic exercise in fibromyalgia syndrome: a systematic review and meta-analysis of randomised controlled trials. Arthritis Res Ther. 2010;12(3):R79.

41. Jones KD, Liptan GL. Exercise interventions in fibromyalgia: clinical applications from the evidence. Rheum Dis Clin North Am. 2009;35(2): 373-391.

42. Busch AJ, Webber SC, Brachaniec M, et al. Exercise therapy for fibromyalgia. Curr Pain Headache Rep. 2011;15(5):358-367.

43. Kelley GA, Kelley KS, Hootman JM, Jones DL. Exercise and global well-being in community-dwelling adults with fibromyalgia: a systematic review with meta-analysis. BMC Public Health. 2010; 10: 198 .

44. Cazzola M, Atzeni F, Salaffi F, Stisi S, Cassisi G, Sarzi-Puttini P. Which kind of exercise is best in fibromyalgia therapeutic programmes? A practical review. Clin Exp Rheumatol. 2010;28(6 Suppl 63): S117-S124.

45. Meyer BB, Lemley KJ. Utilizing exercise to affect the symptomology of fibromyalgia: a pilot study. Med Sci Sports Exerc. 2000;32(12): 1691-1697.

46. Nørregaard J, Lykkegaard JJ, Mehlsen J, Danneskiold-Samsøe B. Exercise training in treatment of fibromyalgia. J Musculoskelet Pain. 1997;5(1):71-79.
47. Mist SD, Jones KD, Carson JW. Yoga Internet Survey in Fibromyalgia: A K23 Subproject. National State of the Science Congress on Nursing Research, 2012 September 13-15, Washington DC, USA.

48. Wahner-Roedler DL, Elkin PL, Vincent A, et al. Use of complementary and alternative medical therapies by patients referred to a fibromyalgia treatment program at a tertiary care center. Mayo Clin Proc. 2005;80(1): 55-60.

49. Langhorst J, Klose P, Dobos GJ, Bernardy K, Häuser W. Efficacy and safety of meditative movement therapies in fibromyalgia syndrome: a systematic review and meta-analysis of randomized controlled trials. Rheumatol Int. 2012;33(1):193-207.

50. nccam.nih.gov [homepage on the Internet]. What is complementary and alternative medicine? National Center for Complementary and Alternative Medicine; 2008 [updated July 2011]. Available from: http:// nccam.nih.gov/health/whatiscam\#definingcam. Accessed October 30, 2012.

51. Wolfe C, Smythe HA, Yunus MB, et al. The American College of Rheumatology 1990 Criteria for the Classification of Fibromyalgia. Report of the Multicenter Criteria Committee. Arthritis Rheum. 1990;33(2): $160-172$.

52. Burckhardt CS, Clark SR, Bennett RM. The fibromyalgia impact questionnaire (FIQ): development and validation. J Rheumatol. 1991;18: 728-733.

53. Calandre EP, Rodriguez-Claro ML, Rico-Villademoros F, Vilchez JS, Hidalgo J, Delgado-Rodriguez A. Effects of pool-based exercise in fibromyalgia symptomatology and sleep quality: a prospective randomised comparison between stretching and Ai Chi. Clin Exp Rheumatol. 2009;27(5 Suppl 56):S21-S28.

54. Ide MR, Laurindo LMM, Rodrigues-Junior AL, Tanaka C. Effect of aquatic-respiratory exercise-based program in patients with fibromyalgia. Int J Rheumat Dis. 2008;11(2):131-140.

55. Higgins JPT, Green S, editors. Cochrane Handbook for Systematic Reviews of Interventions Version 5.1.0 [updated March 2011]. The Cochrane Collaboration; 2011. Available from: http://handbook. cochrane.org. Accessed January 23, 2013.

56. Higgins JP, Thompson SG. Quantifying heterogeneity in a metaanalysis. Stat Med. 2002;21(11):1539-1558.

57. Jadad AR, Moore RA, Carroll D, et al. Assessing the quality of reports of randomized controlled trials: is blinding necessary? Control Clin Trials. 1996;17(1):1-12.

58. Altan L, Korkmaz N, Bingol U, Gunay B. Effect of pilates training on people with fibromyalgia syndrome: a pilot study. Arch Phys Med Rehabil. 2009;90(12):1983-1988.

59. Astin JA, Berman BM, Bausell B, Lee WL, Hochberg M, Forys KL. The efficacy of mindfulness meditation plus Qigong movement therapy in the treatment of fibromyalgia: a randomized controlled trial. J Rheumatol. 2003;30(10):2257-2262.

60. Carbonell-Baeza A, Aparicio VA, Martins-Pereira CM, et al. Efficacy of Biodanza for treating women with fibromyalgia. J Altern Complement Med. 2010;16(11):1191-1200.

61. Carbonell-Baeza A, Romero A, Aparicio VA, et al. Preliminary findings of a 4-month Tai Chi intervention on tenderness, functional capacity, symptomatology, and quality of life in men with fibromyalgia. Am J Mens Health. 2011;5(5):421-429.

62. Carson JW, Carson KM, Jones KD, Bennett RM, Wright CL, Mist SD. A pilot randomized controlled trial of the Yoga of Awareness program in the management of fibromyalgia. Pain. 2010;151(2):530-539.

63. Chen KW, Hassett AL, Hou F, Staller J, Lichtbroun AS. A pilot study of external qigong therapy for patients with fibromyalgia. J Altern Complement Med. 2006;12(9):851-856.

64. Curtis K, Osadchuk A, Katz J. An eight-week yoga intervention is associated with improvements in pain, psychological functioning and mindfulness, and changes in cortisol levels in women with fibromyalgia. J Pain Res. 2011;4:189-201

65. da Silva GD, Lorenzi-Filho G, Lage LV. Effects of yoga and the addition of Tui $\mathrm{Na}$ in patients with fibromyalgia. JAltern Complement Med. 2007;13(10):1107-1113. 
66. Haak T, Scott B. The effect of Qigong on fibromyalgia (FMS): a controlled randomized study. Disabil Rehabil. 2008;30(8):625-633.

67. Hennard J. A protocol and pilot study for managing fibromyalgia with yoga and meditation. Int J Yoga Therapy. 2011(21):109-121.

68. Jones KD, Sherman CA, Mist SD, Carson JW, Bennett RM, Li F. A randomized controlled trial of 8-form Tai Chi improves symptoms and functional mobility in fibromyalgia patients. Clin Rheumatol. 2012;31(8):1205-1214.

69. Liu W, Zahner L, Cornell M, et al. Benefit of Qigong exercise in patients with fibromyalgia: a pilot study. Int J Neurosci. 2012;122(11): 657-664.

70. Lynch M, Sawynok J, Hiew C, Marcon D. A randomized controlled trial of qigong for fibromyalgia. Arthritis Res Ther. 2012;14(4):R178-R189.

71. Mannerkorpi K, Arndorw M. Efficacy and feasibility of a combination of body awareness therapy and qigong in patients with fibromyalgia: a pilot study. $J$ Rehabil Med. 2004;36(6):279-281.

72. Maddali Bongi S, Di Felice C, Del Rosso A, et al. Efficacy of the "body movement and perception" method in the treatment of fibromyalgia syndrome: an open pilot study. Clin Exp Rheumatol. 2011;29(6 Suppl 69): $\mathrm{S} 12-\mathrm{S} 18$

73. Romero-Zurita A, Carbonell-Baeza A, Aparicio VA, Ruiz JR, Tercedor P, Delgado-Fernández M. Effectiveness of a tai-chi training and detraining on functional capacity, symptomatology and psychological outcomes in women with fibromyalgia. Evid Based Complement Alternat Med. 2012;2012:614196.

74. Taggart HM, Arsianian CL, Bae S, Singh K. Effects of Tai Chi exercise on fibromyalgia symptoms and health-related quality of life. Orthop Nurs. 2003;22(5):353-360.

75. Wang $\mathrm{C}$, Schmid $\mathrm{CH}$, Rones $\mathrm{R}$, et al. A randomized trial of tai chi for fibromyalgia. N Engl J Med. 2010;363(8):743-754.

76. Stephens S, Feldman BM, Bradley N, et al. Feasibility and effectiveness of an aerobic exercise program in children with fibromyalgia: Results of a randomized controlled pilot trial. Arthritis Rheum. 2008;59(10): 1399-1406.
77. Anthony KK, Schanberg LE. Juvenile primary fibromyalgia syndrome. Curr Rheumatol Rep. 2001;3(2):165-171.

78. Buskila D. Pediatric fibromyalgia. Rheum Dis Clin North Am. 2009; 35(2):253-261.

79. Gedalia A, García CO, Molina JF, Bradford NJ, Espinoza LR. Fibromyalgia syndrome: experience in a pediatric rheumatology clinic. Clin Exp Rheumatol. 2000;18(3):415-419.

80. Siegel DM, Janeway D, Baum J. Fibromyalgia syndrome in children and adolescents: clinical features at presentation and status at follow-up. Pediatrics. 1998;101(3 Pt 1):377-382.

81. Rudrud L. Gentle Hatha yoga and reduction of fibromyalgia-related symptoms: a preliminary report. Int J Yoga Therap. 2012;(22): 53-57.

82. Meinert CL. Clinical Trials: Design, Conduct, and Analysis. New York: Oxford University Press; 1986.

83. Williams DA, Arnold LM. Measures of fibromyalgia: Fibromyalgia Impact Questionnaire (FIQ), Brief Pain Inventory (BPI), Multidimensional Fatigue Inventory (MFI-20), Medical Outcomes Study (MOS), Sleep Scale, and Multiple Ability Self-Report Questionnaire (MASQ). Arthritis Care Res (Hoboken). 2011;63 Suppl 11:S86-S97.

84. Bennett RM, Friend R, Jones KD, Ward R, Han BK, Ross RL. The revised FM impact questionnaire (FIQR): validation and psychometric properties. Arthritis Res Ther. 2009;11(4):R120.

85. Williams DA, Kuper D, Segar M, Mohan N, Sheth M, Clauw DJ. Internet-enhanced management of fibromyalgia: a randomized controlled trial. Pain. 2010;151(3):694-702.

86. Mease PJ, Clauw DJ, Christensen R, et al; the OMERACT Fibromyalgia Working Group. Toward development of a fibromyalgia responder index and disease activity score: OMERACT module update. J Rheumatol. 2011;38(7):1487-1495.
Journal of Pain Research

\section{Publish your work in this journal}

The Journal of Pain Research is an international, peer-reviewed, open access, online journal that welcomes laboratory and clinical findings in the fields of pain research and the prevention and management of pain. Original research, reviews, symposium reports, hypothesis formation and commentaries are all considered for publication.

\section{Dovepress}

The manuscript management system is completely online and includes a very quick and fair peer-review system, which is all easy to use. Visit http://www.dovepress.com/testimonials.php to read real quotes from published authors. 